\section{Edyrcasaice

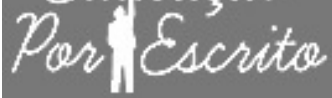

ARTIGO

\section{Editor}

Alexandre Anselmo Guilherme PUCRS, RS, Brasil

\section{Editor Assistente}

Cibele Cheron

PUCRS, RS, Brasil

\section{Editores Associados}

Bruno Antonio Picoli

Universidade Federal da Fronteira Sul, Chapecó, SC, Brasil

Pricila Kohls dos Santos Universidade Católica de Brasília, Brasília, DF, Brasil

Renato de Oliveira Brito

Universidade Católica de Brasilia, Brasilia, DF, Brasil

Elisa Ustarroz

PUCRS, Porto Alegre, RS, Brasil

\section{ISSN 2179-8435}

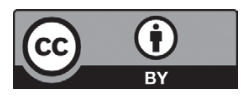

Este artigo está licenciado sob forma de uma licença Creative Commons Atribuição 4.0 Internacional, que permite uso irrestrito, distribuição e reprodução
em qualquer meio, desde que a publicaçăo original em qualquer meio, descorretamente citada.

\title{
Uma breve síntese do perfil de alunos bolsistas em uma universidade comunitária do RS: contribuições para a trajetória acadêmica na graduação
}

\author{
A brief summary of the scholarship student's profile in a communitary university \\ of Rio Grande do Sul: contributions for the academic trajectory in graduation
}

\author{
Malu Santarem Schuh ${ }^{1}$ \\ Maria Elisabete Machado 1 \\ Alam de Oliveira Casartelli ${ }^{1}$ \\ ${ }^{1}$ Pontifícia Universidade Católica do Rio Grande do Sul (PUCRS), Porto Alegre, RS, Brasil.
}

\section{RESUMO}

O presente artigo objetiva apresentar uma breve síntese do perfil de alunos bolsistas matriculados nos cursos de graduação de uma universidade comunitária. Entende-se que ao conhecer tal realidade será possível contribuir para com as suas trajetórias de formação. Nessa perspectiva, no decorrer do estudo, aborda-se a trajetória dos alunos bolsistas que acessam o campus universitário por meio de políticas públicas, com vistas a compreender as suas estratégias para permanecer e concluir a sua formação, como processo relevante para o progresso profissional. Para a construção desse estudo, recorreu-se ao aporte teórico de estudiosos como Dubar (1996, 2005), Josso (2007), Morosini (2006), Ristoff (2014) e Zabalza (2004), além do amparo legal que subsidia a existência de programas que permitem o acesso desse público à graduação. Para tanto, promoveu-se um estudo de caso (YIN, 2010) ambientado na Pontifícia Universidade Católica do Rio Grande do Sul (PUCRS), por meio de uma pesquisa quantitativa (MALHOTRA, 2006) cujo instrumento utilizado foi um questionário direcionado a uma amostra representativa de alunos, a fim de quantificar as informações. A análise e a interpretação dos dados ocorreram por meio de estatísticas descritivas, de acordo com o que preconiza Malhotra (2006). Como principais resultados, elencam-se a caracterização do perfil de alunos bolsistas na universidade, os desafios e as possibilidades no decorrer da trajetória acadêmica, envolvendo majoritariamente estudantes/trabalhadores.

Palavras-chave: Trajetória acadêmica. Universidade. Graduação. Alunos bolsistas.

\section{ABSTRACT}

The present article has the objective to show a brief summary about scholarship students profile enrolled in the graduation courses of a communitary university. We understand that to know these student's reality will 
be possible to contribute with their trajectories of formation. During this study we'll discuss the scholarship student's trajectory, accessing them the university campus through public policies, as well to understand these strategies to stand and conclude their formation. Beyond that, we analyze this formation importance for their professional progress. For the construction of this study, we used theoric contribution from this referred authors: Dubar (1996; 2005), Josso (2007), Morosini (2006), Ristoff (2014) e Zabalza (2004), beyond the legal contribution that stands the existence of programs that allow the access of this people to graduation. For that, we realize a study of a case (YIN, 2010) at PUCRS, through quantitative research (MALHOTRA, 2006), which the instrument we used was a quiz directed for a representative sample of students to quantify data. An analysis and interpretation of data occurred through descritive statistics according to Malhotra (2006). As main results we have the profile characterization of university scholarship students, the challenges and possibilities during the academic trajectory as well, considering that they are students/workers as majority.

Keywords: Academic trajectory. University. Graduation. Scholarship students.

\section{Introdução}

presente trabalho é oriundo da inquietação de pesquisadores do campo educacional que estudam a trajetória de alunos de graduação. À vista disso, ao focar nossas pesquisas no Ensino Superior brasileiro, delineou-se uma problemática que assola constantemente as universidades - especialmente, as instituições de cunho comunitário: os grandiosos índices de evasão de alunos bolsistas, os quais, como jovens estudantes, com idades entre dezoito e vinte e quatro anos, sonham com um futuro melhor e compreendem que a educação superior sintetiza a melhor maneira de atingi-lo. Como é de conhecimento, nos últimos anos, o governo brasileiro investiu em programas de acesso ao Ensino Superior, o que viabilizou o ingresso de alunos de classes populares nesse nível educacional. Por meio das ações governamentais experimentadas, pôde-se identificar o aumento do acesso a bens e a serviços da classe média e baixa brasileira, dentre os quais, a possibilidade de ingresso às universidades. Nesse panorama,

Nunca houve tantos jovens das classes média e baixa cursando universidades, reduzindo quantitativamente a desigualdade no ensino superior do país. Em 1994, havia 1,7 milhão de pessoas em curso superior. Em 2014 esse número saltou para 7 milhões, sendo que 4,4 milhões são jovens e, desses, 2,3 milhões são das classes média e baixa (UNE, [2015]). 
Em contrapartida, a história da educação superior brasileira evidencia que, durante muitos anos, o acesso à universidade se destinou somente a alguns poucos sujeitos de camadas socioeconômicas mais altas que puderam estudar em escolas privadas - ditas de qualidade. Diante disso, com a popularização da universidade, visibilizou-se a ocupação dos bancos acadêmicos pelas mais distintas classes sociais e, consequentemente, por discentes que estudaram na rede de educação básica pública ou com bolsas de estudos em escolas privadas. Com isso, surgiu um novo contexto no ambiente universitário que precisa ser investigado.

A partir da evidente pluralidade presente nos espaços universitários, a instituição universitária deve se repensar para contemplar a formação de diferentes públicos em seu espaço - ou seja, sujeitos com diferentes níveis de ensino e de cultura e sujeitos que dividem o seu tempo entre estudo, família e trabalho. Ademais, mesmo detentores desse direito, por diversas razões, o Ensino Superior representava-lhes uma utopia. Assim, esses universitários trazem consigo para dentro do espaço acadêmico o desconhecimento sobre a universidade, o que constitui a instituição de educação e quais as suas possibilidades dentro dela. Apesar da empolgação inicial originada pelos programas de ingresso ao ensino superior, o direito dos universitários ficou suscetível a ações pontuais dos governos presentes no poder, a investimentos e/ou ao corte de gastos públicos, não consistindo, portanto, em uma conquista pelo direito à educação enquanto cidadão brasileiro. Para tanto, fica clara a necessidade de conhecer esse novo contexto para possibilitar aos universitários a educação superior de qualidade, cuja permanência e conclusão também sejam asseguradas.

Nos primeiros anos do século XXI, a educação superior brasileira sofreu grandes modificações - principalmente, no que se refere ao perfil dos acadêmicos - as quais podem ser atribuídas aos programas de incentivo ao Ensino Superior do Governo Federal, que são os responsáveis por reconfigurar o perfil dos acadêmicos nos cursos de graduação brasileiros. No cenário que se desenha, infere-se que o processo de democratização da educação superior não deve estar atrelado apenas ao ingresso, mas sim à reflexão aprofundada e à crítica sobre a trajetória acadêmica dos alunos bolsistas, tendo em vista a sua permanência e a sua conclusão nos cursos de graduação.

Nesse sentido, convém pensar em estratégias para a permanência dos alunos bolsistas matriculados nos cursos de graduação. Por conseguinte, a principal indagação que este artigo se propõe busca analisar a trajetória acadêmica de alunos bolsistas matriculados em cursos de graduação de uma universidade comunitária. Portanto, torna-se necessário o aprofundamento acerca da temática na intenção de abranger a qualidade no processo de formação dos alunos e a democratização da Educação Superior, uma vez que os discentes devem atender a outras exigências (para além da condição de universitários), como prover o próprio sustento e/ou cumprir obrigações familiares, por exemplo. Em razão disso, 
Para os professores universitários, considerar esse aspecto é fundamental e, apesar do que poderia parecer, é algo extremamente novo, já que, no melhor dos casos, sabemos apenas como nossa identidade profissional se construiu a partir dos conteúdos científicos da disciplina que lecionamos. No entanto a dimensão pessoal de como os alunos aprende, isso é "alheio" ao espaço de preocupações e saberes do professor (ZABALZA, 2004, p. 188).

A fala de Zabalza (2004) sinaliza a importância de conhecer o aluno que está presente em aula para que o processo de sua formação seja de fato significativo, e para que isso aconteça, cabe considerar as dimensões pessoais da vida desse sujeito. Para tanto, revela-se de suma relevância que a trajetória acadêmica individual seja um elemento constituinte dessa construção.

\section{Conceitos importantes}

Para a apresentação da fundamentação teórica, importa fazer referência aos conceitos fundantes deste artigo que visam direcionar o estudo para aspectos que acreditamos ser proveitosos para a compreensão desse trabalho quanto à educação superior. Além do mais, torna-se pertinente elaborar uma síntese das legislações que originaram os programas federais de incentivo ao curso superior. Definiremos - ainda que brevemente - a distinção que ocorre entre as universidades comunitárias de outras Instituições de Ensino Superior (IES). Logo, a análise reflexiva de tais conceitos é imprescindível para que se identifiquem possíveis avanços na efetivação da permanência dos alunos bolsistas no Ensino Superior.

\subsection{A importância das trajetórias}

A importância da trajetória surge da necessidade de conhecer o aluno bolsista por meio de sua história acadêmica - ou seja, a análise de seu percurso de formação na universidade permite a criação de estratégias de permanência por parte das IES, uma vez que assim se pode averiguar as especificidades e as demandas dos alunos presentes no campus. Diante disso, recorreu-se a autores da teoria social para elencar subsídios à compreensão que queremos evidenciar.

Dubar (1996) contextualiza o entendimento acerca das trajetórias sob dois aspectos: a trajetória objetiva, definida como a sequência das posições sociais ocupadas durante a vida, mediada por categorias estatísticas e condensada em uma tendência geral (ascendente, descendente, estável); e a trajetória subjetiva, expressa em diversos relatos biográficos, por meio de categorias inerentes que remetem a mundos sociais e condensáveis em formas identitárias heterogêneas. Isso tudo oportuniza ponderar que, na perspectiva de Dubar (2005), a trajetória de cada um dos sujeitos 
é composta por suas histórias, compreendida por passados e por vivências que consequentemente incidem em suas identidades atuais.

$\mathrm{Na}$ mesma ótica sobre trajetórias, Josso $(2007$, p. 420) leciona que ela "põe em cena um ser-sujeito às voltas com as pessoas, com os contextos e com ele-mesmo, em uma tensão permanente entre os modelos possíveis de identificação com o outro (conformização) e as aspirações à diferenciação (singularização)". Logo, é fundamental que se compreenda a trajetória dos alunos bolsistas para que a universidade possa construir estratégias para garantir a sua permanência.

Assim, tenciona-se que a trajetória acadêmica dos alunos bolsistas seja um elemento constituinte da construção de uma formação que, de fato, traduza a sua realidade. Na observação de Dubar (2005), cada um dos sujeitos abarca histórias, com passados e com vivências que também pesam em suas identidades atuais - ou melhor, não se definem apenas em função de suas histórias atuais, mas constituem-se a partir de sua trajetória, tanto pessoal como social. Portanto, a trajetória de vida dos sujeitos tem muito a ver com o processo de socialização dentro do contexto de ensino, pois cada um carrega consigo sentimentos, histórias, experiências singulares que influenciam no seu processo de formação e na forma com que apreende o conhecimento na universidade. Na sequência, vamos desvelar as legislações e os programas federais que impulsionaram a emergência desse contexto no cenário universitário, mas que não asseguraram elementos fundamentais para a sua permanência.

\subsection{Fies e Prouni: uma breve descrição dos programas}

Entre as políticas de apoio ao acesso à educação superior que se desenvolveram pelo Governo Federal, destacam-se o Fundo de Financiamento Estudantil do Ensino Superior (Fies) e o Programa Universidade para Todos (Prouni). Nesse âmbito, ampliaremos o diálogo sobre tais programas, que são essenciais para o desencadeamento da problemática. Inicialmente, o Fies foi criado em 1999, por meio de uma medida provisória que posteriormente foi convertida na Lei ${ }^{\circ}{ }^{\circ}$ 10.260/2001. Configura um programa destinado a financiar prioritariamente o Ensino Superior para estudantes matriculados em instituições de Ensino Superior não gratuitas com avaliação positiva nos processos conduzidos pelo Ministério da Educação (MEC). Trata-se do mais importante instrumento de financiamento estudantil atualmente existente. Por meio do Fies, o Governo Federal assume os gastos com matrícula e mensalidades do estudante durante toda a graduação.

De acordo com o perfil e o interesse do contratante, o valor financiado varia de $50 \%$ a $100 \%$ do montante total. O reembolso do capital inicia-se após período de carência - isso significa após a conclusão do curso. A taxa de juros sobre o montante financiado é fixa, da ordem de 3,4\%. São elegíveis estudantes cuja renda familiar bruta total não ultrapasse vinte salários mínimos. Dá-se prioridade aos estudantes melhor colocados no Exame Nacional do Ensino 
Médio (Enem). O financiamento possui a particularidade de poder ser combinado à bolsa do Prouni, ou seja, o estudante que faz jus à bolsa parcial do referido programa pode solicitar o financiamento do montante a seu cargo por meio do Fies. Assim, procura-se garantir o acesso e a permanência na educação superior dos estudantes de baixa renda. Já o Prouni foi criado também por meio de uma medida provisória, datada em 2004, cuja Lei que institui de fato o programa - a de $\mathrm{n}$ o 11.096 - foi promulgada em 13 de janeiro de 2005. Outrossim,

Art. 1-_Fica instituído, sob a gestão do Ministério da Educação, o Programa Universidade para Todos PROUNI, destinado à concessão de bolsas de estudo integrais e bolsas de estudo parciais de $50 \%$ (cinquenta por cento) ou de $25 \%$ (vinte e cinco por cento) para estudantes de cursos de graduação e sequenciais de formação específica, em instituições privadas de ensino superior, com ou sem fins lucrativos (BRASIL, 2005).

Ao contrário do que ocorre com o Fies, para validar o direito à bolsa do Prouni, o aluno deve ter sido aprovado no Enem para o curso escolhido, com a possibilidade de escolher entre duas opções de graduação. Além disso, não é necessário o reembolso de valores, por se tratar de uma bolsa de estudos. Portanto, os programas de incentivo ao acesso à graduação foram fundamentais para desencadear o ingresso desse perfil de alunos nas IES brasileiras - e, consequentemente, nas universidades comunitárias. Entretanto, cabe uma crítica a ambos, já que regulamentam apenas o acesso, determinando lacunas quanto à permanência de estudantes de baixa renda nas instituições, os quais precisam arcar com os custos de sua manutenção, como deslocamento e alimentação.

\subsection{Instituições de Ensino Superior: são todas iguais?}

No cenário brasileiro há IES de diferentes naturezas e com distintos objetivos. Essas instituições caracterizam-se por centros universitários, faculdades, polos de ensino a distância e universidades. De acordo com o que dita o artigo no 52 da Lei de Diretrizes e Bases (LDB), as universidades compreendem "instituições pluridisciplinares de formação dos quadros profissionais de nível superior, de pesquisa, de extensão e de domínio e cultivo do saber humano" (BRASIL, [1996]). Por conseguinte, na busca pela formação de qualidade, a universidade constitui-se como ambiente adequado à construção da cidadania, posto que congloba as dimensões essenciais para o desenvolvimento de sujeitos críticos - a saber, o ensino, a pesquisa e a extensão.

Contudo, as universidades também registram distinções: conforme preconiza a Enciclopédia de Pedagogia Universitária, organizada por Morosini (2006), elas podem ser coorporativas, de massa, liberais híbridas, multicampi, virtuais, globais e comunitárias. As universidades comunitárias recebem verbas públicas, e em contrapartida devem 
comprovar finalidade não lucrativa e investir o seu lucro em educação (MOROSINI, 2006). A Associação Brasileira das Universidades Comunitárias (ABRUC, 2015) informa que "Tratam-se de instituições sem fins lucrativos, que desenvolvem ações essencialmente educacionais, como ensino, pesquisa e extensão, com notória excelência em suas atividades". Portanto, as universidades comunitárias são definidas a partir de seu papel social e de seu comprometimento com uma proposta para a formação acadêmica de qualidade.

Nesse sentido, muitos alunos buscam vagas em cursos de graduação de referidas instituições por reconhecerem a qualidade de seu ensino e por entenderem que, por meio delas, terão melhores condições de emprego no futuro. Salienta-se que esse entendimento ocorre pelo forte vínculo que tais universidades têm com suas comunidades, constituindo-se em um patrimônio público da sociedade na qual está inserida (CONSÓRCIO DAS UNIVERSIDADES COMUNITÁRIAS GAÚCHAS, 2016). Entretanto, é de conhecimento que a evasão em qualquer nível de ensino traz implicações negativas no desenvolvimento humano dos estudantes e acarreta severas consequências sociais e econômicas, tanto para os alunos como também para as instituições de ensino. A partir dessa preocupação, elencaremos dados de uma pesquisa realizada pelos autores Alam de Oliveira Casartelli e Malu Santarem Schuh, realizada entre 2015 e 2017, que forneceram subsídios para a construção de estratégias de permanência desses alunos.

\section{Procedimentos metodológicos}

Haja vista o conhecimento acerca da trajetória acadêmica dos alunos bolsistas nos cursos de graduação, uma pesquisa quantitativa conclusiva foi elaborada, por meio de estatísticas descritivas ${ }^{1}$ com aportes teóricos e metodológicos referenciados no paradigma crítico-dialético. A análise estatística dessa etapa ocorreu por meio da distribuição de frequências. Para Malhotra (2006), a distribuição de frequências consiste em um método que permite agrupar dados em classes, a fim de viabilizar a sua quantidade ou a sua porcentagem. Assim, consegue-se resumir ou visualizar um conjunto de informações, sem considerar os valores individuais. Com isso, buscamos conhecer em profundidade o contexto em que a pesquisa foi realizada, tendo em vista a construção de novos significados que emergem do cenário investigado.

Para tanto, enviamos um questionário aos estudantes de graduação da Pontifícia Universidade Católica do Rio Grande do Sul (PUCRS), com a finalidade de conhecer as suas trajetórias de formação. Tomamos o questionário semiestruturado como mote para esse estudo, pois concordamos com o pensamento de Gil (2009, p. 128), que ensina que o questionário constitui-se como "uma técnica de investigação composta por um número mais ou menos

\footnotetext{
1 Busca-se na pesquisa quantitativa-descritiva a possibilidade de mensuração e de descrição dos dados.
} 
elevado de questões apresentadas por escrito às pessoas, tendo por objetivo o conhecimento de opiniões, crenças, sentimentos, interesses, expectativas, situações vivenciadas". Com base nas respostas dos alunos, detectaram-se elementos importantes sobre as trajetórias universitárias, como relata o próximo item deste artigo.

\section{Resultados e discussões}

Após a etapa inicial - que compreendeu a coleta dos dados do questionário - as respostas foram tabuladas por meio do aplicativo Qualtrics. Optamos, então, por revelar os resultados obtidos em forma de gráficos, inferindo que as ilustrações facilitam a compreensão dos achados. O questionário foi enviado para 18.573 pessoas, dentre as quais, alunos matriculados nos cursos de graduação da instituição em análise. Desses, obtivemos 727 respostas. Ressalta-se que o questionário para a realização da coleta de dados ficou disponível nas duas primeiras semanas do mês de novembro - ou seja, do dia 3 ao dia 15 de novembro de 2016.

O Gráfico 1 exibe o gênero informado na amostra: os respondentes foram, na maioria, do sexo feminino, $61 \%$ mulheres e $39 \%$ homens.

Gráfico 1 - Porcentagem do sexo da amostra.

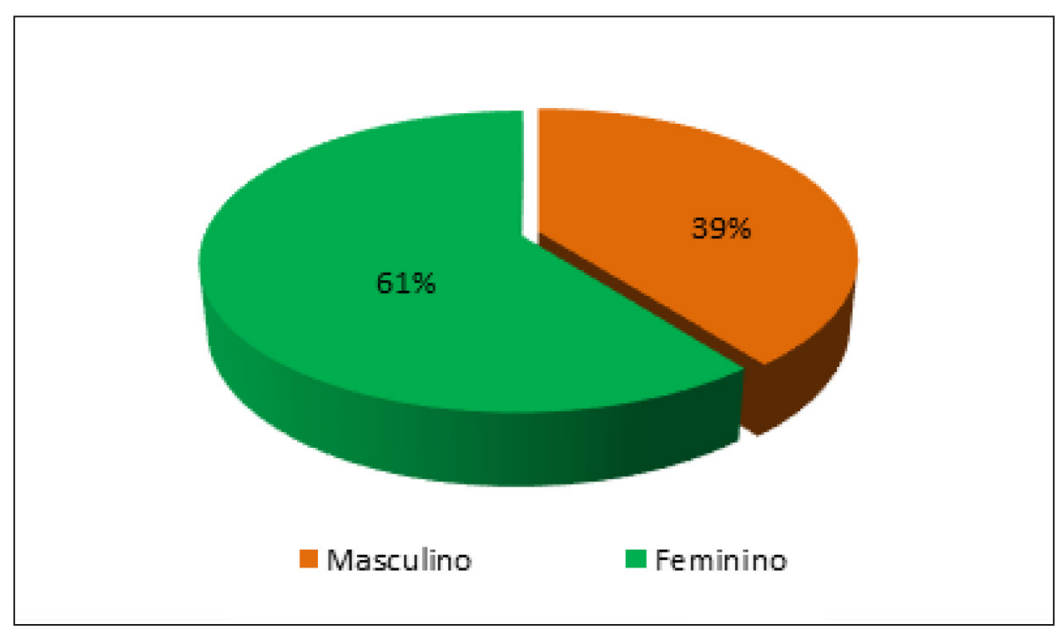

Fonte: Elaborado pelos autores. 
O Gráfico 2 evidencia a faixa etária dos alunos respondentes. Percebe-se que a maioria dos alunos contabiliza entre 18 e 24 anos, representando mais da metade da amostra, com 53\%. Já os alunos entre 25 e 30 anos representam uma parcela significativa de $28 \%$ da amostra. Outro dado relevante explana que $19 \%$ dos universitários têm mais de 30 anos de idade. Não houve respondentes com idade inferior a 18.

Gráfico 2 - Porcentagem da faixa etária

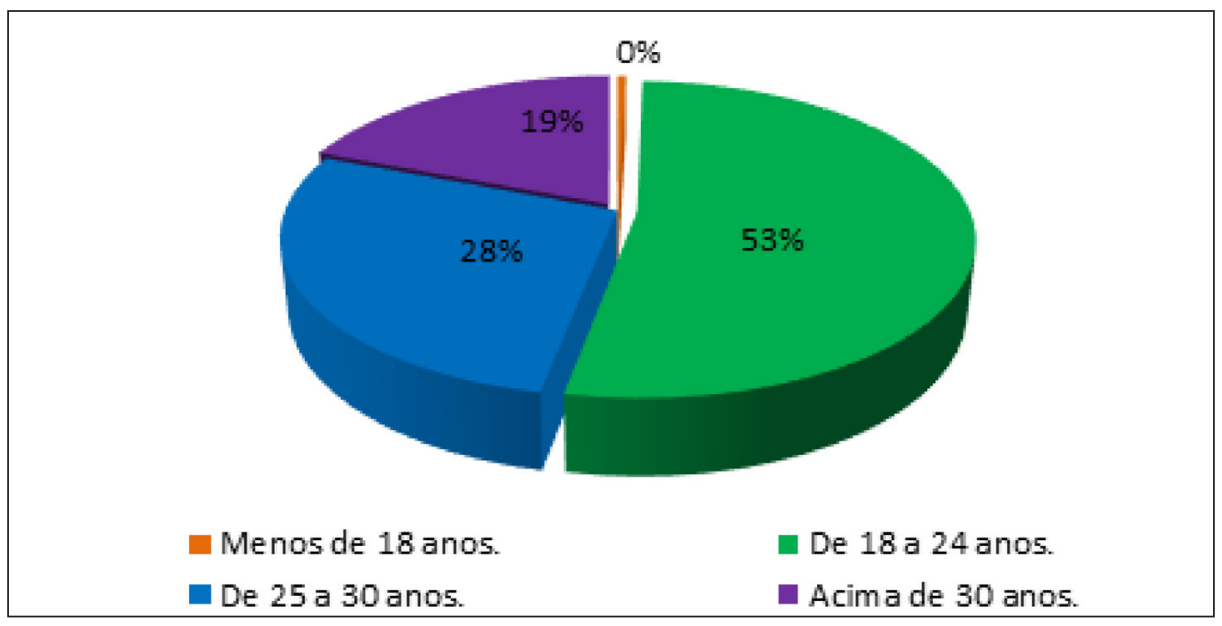

Fonte: Elaborado pelos autores.

O Gráfico 3 revela que $81 \%$ da amostra se define como de pele branca, enquanto apenas $11 \%$ dos entrevistados se apresentam como pardos ou mulatos, e 7\% negros. Isso significa que, apesar de ter aumentado o ingresso de pessoas negras nas universidades brasileiras nos últimos anos, o dado ainda expressa o grande descompasso no sentido da democratização do Ensino Superior. Os indicadores sociais do Instituto Brasileiro de Geografia e Estatística (IBGE, 2015) mostram que apenas $12,5 \%$ da população negra entre dezoito e vinte e quatro anos está na universidade, enquanto $26,5 \%$ da população branca na mesma faixa etária tem acesso ao Ensino Superior.

Já o Gráfico 4 sinaliza que 78\% dos alunos frequentaram o Ensino Médio em instituição pública, seguidos por $14 \%$ que cursaram em escola privada. 
Gráfico 3 - Raça/etnia dos universitários

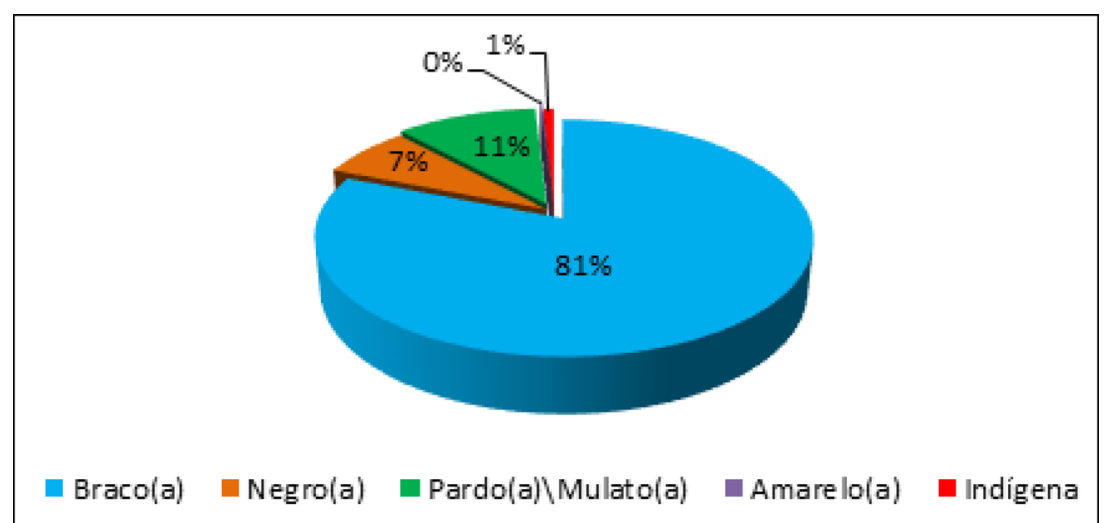

Fonte: Elaborado pelos autores.

Gráfico 4 - Tipo de escola em que cursou o Ensino Médio

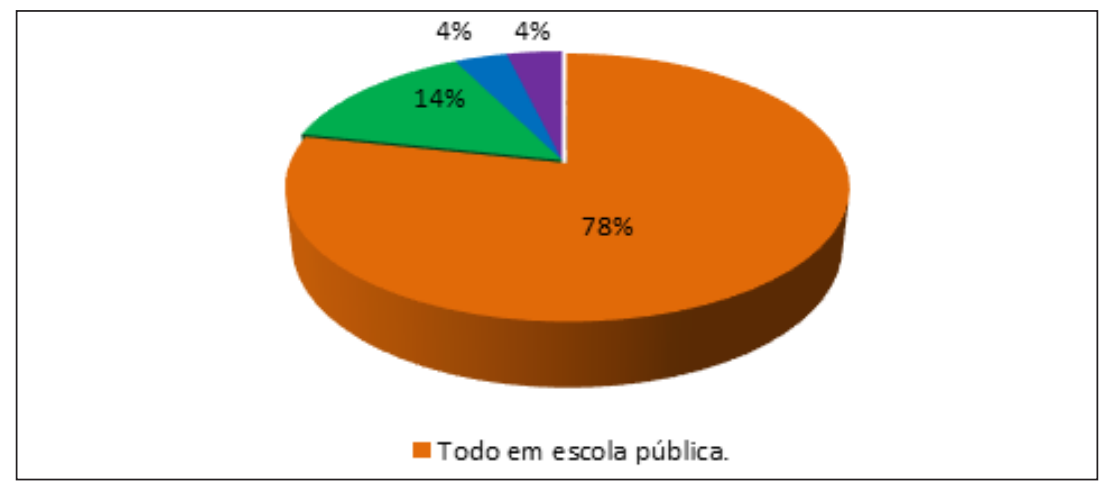

Fonte: Elaborado pelos autores.

Vale destacar, com relação ao Ensino Médio, que $81 \%$ dos alunos cursaram esse nível de ensino de forma tradicional; 9,15\% concluíram na modalidade de Educação de Jovens e Adultos (EJA); e 9,2\% realizaram algum curso técnico profissionalizante antes de seu ingresso na universidade. 
Gráfico 5 - Situação atual de trabalho

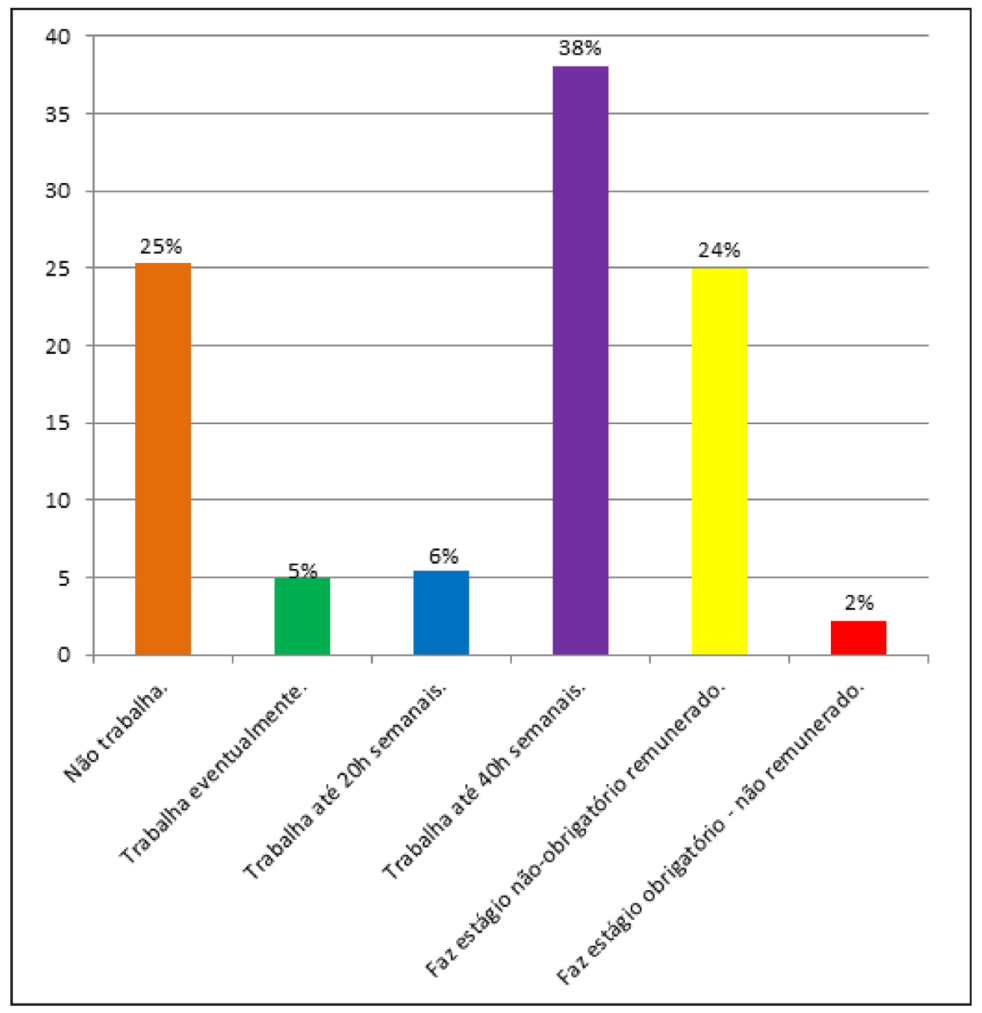

Fonte: Elaborado pelos autores.

Constatou-se que $38 \%$ dos sujeitos da amostra trabalham em turno integral e conciliam a atividade com o curso de graduação. Além disso, $25 \%$ da amostra que não trabalha pode estar vivenciando a situação de desemprego, em virtude da crise política e econômica pela qual o País passa nesse período² ${ }^{2}$ Em consonância com o relatório da Pesquisa

2 A crise no Brasil, que atinge os cidadãos das camadas mais desfavorecidas, acarreta desemprego e falta de oportunidades. Como pode ser consultado em diversas matérias tanto em âmbito nacional como internacional. Ver mais em: https://brasil.elpais.com/tag/desempleo. 
Nacional por Amostra em Domicílios Contínua (PNAD) de 2015, “o desemprego geral passou, nos últimos 12 meses, de $6,5 \%$ para $9 \%$. Mas o salto foi de $14 \%$ para $19 \%$, no mesmo período, para os brasileiros de 18 a 24 anos". Nesse ponto de vista, a falta de experiência também pode representar um elemento contribuinte para o aumento desse índice.

Por outro lado, $24 \%$ dos alunos estão realizando estágios não obrigatórios remunerados, o que coopera para a manutenção de suas despesas e concomitantemente constrói a bagagem profissional em sua área de atuação. Além do mais, $6 \%$ da amostra relatou trabalhar vinte horas semanais; $5 \%$ trabalham eventualmente; e $2 \%$ estão em fase de realização dos estágios obrigatórios de seus cursos de graduação. A importância desses dados reside em mostrar quem são os alunos bolsistas que ingressaram na universidade e como se organizam para dar conta da realidade posta a seus cotidianos. Assim, os próximos gráficos listarão informações alusivas às trajetórias acadêmicas dos alunos. O Gráfico 6 ilustra o principal motivo que impulsionou os universitários a buscarem um curso de Ensino Superior.

Gráfico 6 - Principal motivo que levou os alunos bolsistas a fazer um curso de nível superior

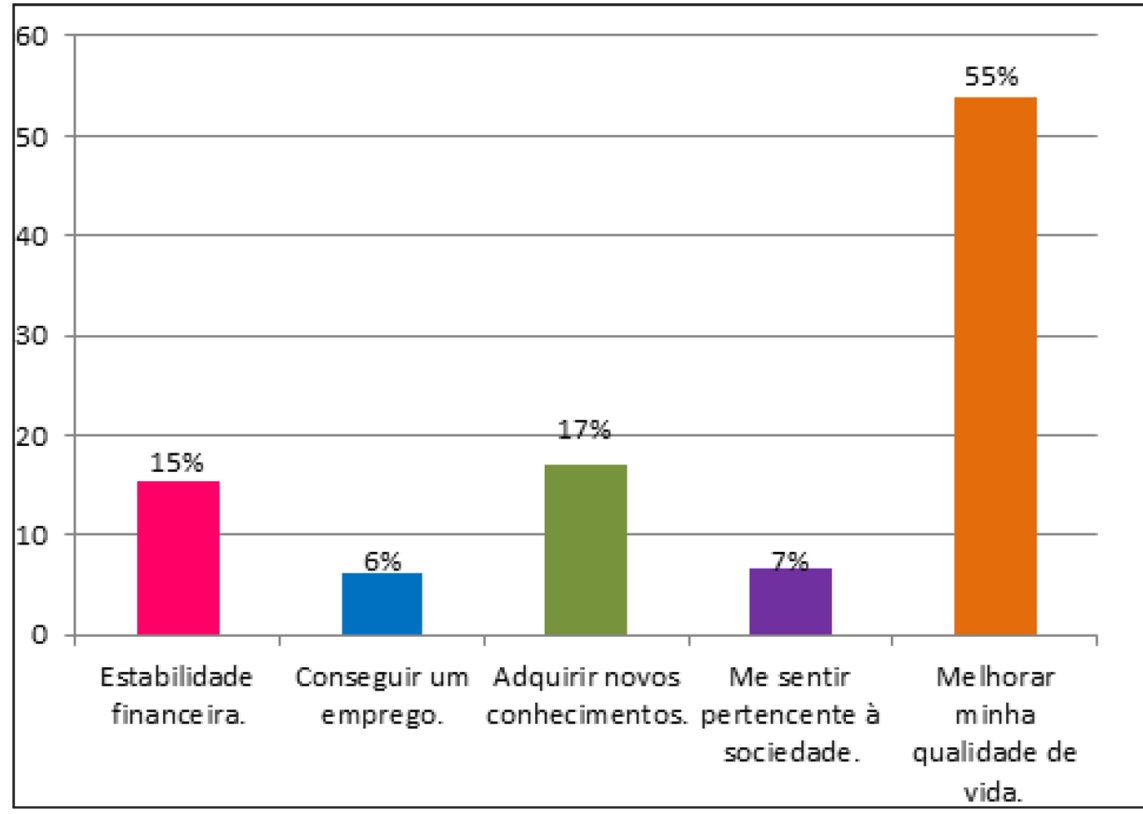

Fonte: Elaborado pelos autores. 
55\% dos alunos buscaram o Ensino Superior para melhorar a sua qualidade de vida, enquanto 17\% objetivaram a aquisição de novos conhecimentos; já $15 \%$ visaram à estabilidade financeira, o que sugere que estão preocupados com o seu futuro e com o seu bem-estar social e entendem que o Ensino Superior representa o principal meio para tais conquistas. Ademais, 7\% recorreram ao Ensino Superior para sentir-se pertencente à sociedade; e $6 \%$ para conseguir emprego. Como se visualizou no Gráfico 4, 78\% dos alunos bolsistas frequentaram o Ensino Médio da rede pública, e de acordo com as ideias de Ristoff (2014), os alunos com tal característica, e ainda com renda familiar de até cinco salários mínimos, optam, geralmente, por cursos da área de Ciências Humanas e da área de Ciências Sociais Aplicadas, o que coaduna com as respostas da amostra e retrata uma realidade presente nos campi brasileiros. Outro dado da realidade brasileira refere-se ao ingresso dos alunos no Ensino Superior por meio dos programas governamentais de incentivo a esse nível de ensino, como o Prouni e Fies. O Gráfico 7 indica que as bolsas do Prouni denotam a principal fonte de subsídio para que os alunos possam cursar a graduação.

As propostas para os estudantes que necessitam de apoio financeiro para os estudos superiores atualmente estão vinculadas ao PROUNI e a outros tipos de bolsa ou mesmo financiamento como FIES e a outros modelos alternativos criados pela própria IES (ROCHA, 2011, p. 175).

Isso reitera a importância de fomentar políticas públicas de acesso ao Ensino Superior, embora se entenda a necessidade de discussão sobre aspectos que propiciem também condições de permanência para os alunos em seus cursos.

Gráfico 7 - Tipos de bolsa ou de financiamento utilizados pelos universitários

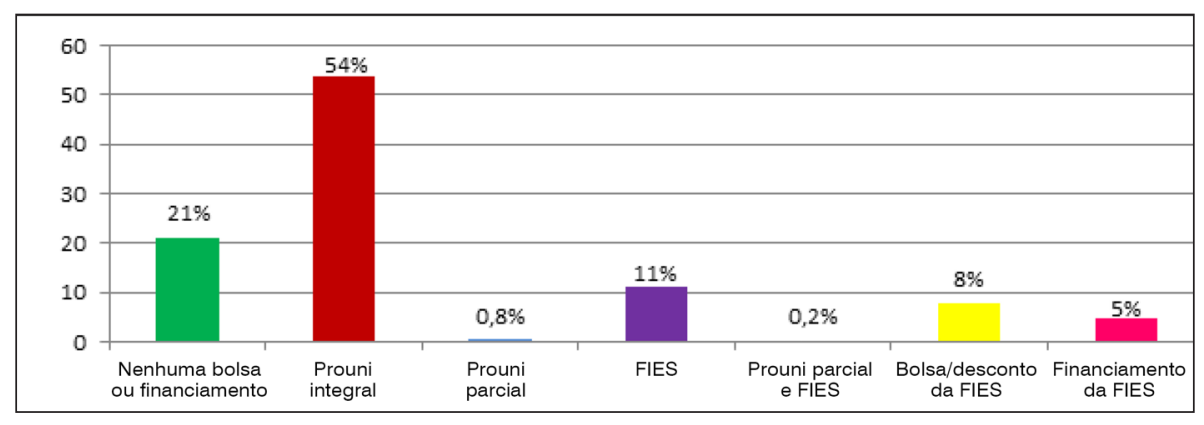

Fonte: Elaborado pelos autores. 
Finalmente, destaca-se a relevância do fortalecimento desses programas - em especial, em tempos de crise econômica e política - uma vez que abrangem a principal via de acesso ao Ensino Superior.

\section{Considerações finais}

Ao refletir sobre um dos objetivos deste artigo - apresentar uma breve síntese sobre o perfil de alunos bolsistas matriculados nos cursos de graduação de uma universidade comunitária - concluiu-se que compreendem estudantes provenientes do ensino público, jovens trabalhadores que perceberam no Ensino Superior a possibilidade de melhorar suas condições de vida. Diante disso, cabe aos gestores das universidades e aos professores conhecer a realidade do estudante/trabalhador, pois o conhecimento sobre o perfil desse alunado contribuirá para que a universidade - como formadora de opinião - possa minimizar o potente número de evasão desse perfil discente que luta para finalizar sua trajetória universitária.

Referente ao objetivo principal dessa escrita - analisar a trajetória acadêmica de alunos bolsistas matriculados em cursos de graduação de uma universidade comunitária - é possível inferir que esses graduandos precisam aliar as suas tarefas estudantis com as tarefas inerentes a vida adulta, como a de manter o próprio sustento, bem como o sustento de seus familiares. Além disso, é fato que esses estudantes, por não terem conhecimento sobre a universidade, desconhecem outras possibilidades de aprendizagem, como o ensino, a pesquisa e a extensão.

Por fim, concluímos que esse movimento deve contemplar todos os sujeitos que transitam no meio acadêmico: técnicos, docentes, discentes e pesquisadores devem estar cientes das transformações ocorridas nesse ambiente e, portanto, iniciar um movimento convergente para a democratização e a qualidade do Ensino Superior.

É de conhecimento que, na busca pelo diploma de nível superior, os jovens estudantes bolsistas encontram-se constantemente tensionados entre a jornada de trabalho e a formação universitária. Em suma, reforça-se neste artigo a tese de que a universidade precisa expressar posicionamento crítico para garantir o direito à educação superior dos cidadãos brasileiros, o que se conquista na medida em que os alunos estruturam pensamentos críticos e reflexivos sobre a realidade que se descortina. Enfatiza-se, então, a busca pela emancipação e pela autonomia dos sujeitos nesse espaço de formação e de ensino, do qual por muito tempo estiveram à margem, por questões sociais, políticas, econômicas e culturais. 


\section{Referências}

ASSOCIAÇÃO BRASILEIRA DAS UNIVERSIDADES COMUNITÁRIAS (ABRUC). Quem somos, Brasília, DF, 2015.

Disponível em: http://www.abruc.org.br/. Acesso em: 25 out. 2016.

BRASIL. Lei no 9.364, de 20 de dezembro de 1996. Estabelece as diretrizes e bases da educação nacional. Disponível em: http:// www.planalto.gov.br/ccivil_03/_Leis/L9394.htm. Acesso em: 22 maio 2017.

BRASIL. Lei no 11. 096, de 13 de janeiro de 2005. Institui o Programa Universidade para Todos - PROUNI, regula a atuação de entidades beneficentes de assistência social no ensino superior; altera a Lei $\mathrm{n}$ - -10.891 , de 9 de julho de 2004, e dá outras providências. Disponível em: http://www.planalto.gov.br/ccivil_03/_ato2004-2006/2005/lei/L11096.htm. Acesso em: 25 jun. 2017. https://doi.org/10.11606/d.48.2016.tde-01082016-153859

CONSÓRCIO DAS UNIVERSIDADES COMUNITÁRIAS GAÚCHAS (COMUNG). Sobre o COMUNG. Porto Alegre, RS, 2016. Disponível em: http://www.comung.org.br/sobre/exibir/comung. Acesso em: 18 nov. 2016.

DUBAR, Claude. A socialização: construção das identidades sociais e profissionais. Porto editora, 1996. https://doi.org/10.1590/ s0101-73301998000100002

DUBAR, Claude. Trajetórias social e formas identitárias: alguns esclarecimentos conceituais e metodológicos. Disponível em: http://www.scielo.br/scielo.php?script=sci_arttext\&pid=S0101-73301998000100002\&lng=en\&nrm=iso\&tlng=pt. Acesso em: 20 abr. 2017.

GIL, Antônio Carlos. Métodos e técnicas de pesquisa social. 5. ed. São Paulo: Atlas, 1999

INSTITUTO BRASILEIRO DE GEOGRAFIA E ESTATÍSTICA (IBGE). Pesquisa Nacional por amostra de domicílios (PNAD). Rio de Janeiro, 2015. Disponível em: http://www.ibge.gov.br/home/estatistica/pesquisas/pesquisa_resultados.php?id_pesquisa=149. Acesso em: 19 nov. 2016. https://doi.org/10.17143/ciaed/xxiilciaed.2017.00322

JOSSO, Marie-Christine. A transformação de si a partir da narração de histórias de vida. Porto Alegre, 2007.

MALHOTRA, Naresh. Pesquisa de marketing: uma orientação aplicada. 4. ed. Porto Alegre: Bookman, 2006.

MOROSINI, Marilia Costa (org.). Enciclopédia de pedagogia universitária. Porto Alegre: FAPERGS/RIES, 2006.

RISTOFF, Dilvo. Novo perfil do campus brasileiro: uma análise do perfil socioeconômico do estudante de graduação. Rev. Avaliação, Sorocaba, SP, v. 19, n. 3, p. 723-747, 2014. Disponível em: http://periodicos.uniso.br/ojs/index.php?journal=avaliacao\&page=article\& op=view\&path\%5B\%5D=2058\&path\%5B\%5D=1796. Acesso em: 19 ago. 2015. https://doi.org/10.1590/s1414-40772014000300010 
ROCHA, Maria Aparecida Marques da. Processo de inclusão ilusória: o jovem bolsista universitário. Jundiaí: Paco, 2011.

UNIÃO NACIONAL DOS ESTUDANTES. Jovens de classe média e baixa avançam nas universidades. São Paulo: União nacional dos estudantes, 2015. Disponível em: http://www.une.org.br/2015/01/jovens-de-classe-medica-e-baixa-avancam-nasuniversidades/. Acesso em: 13 jun. 2017. https://doi.org/10.11606/d.96.2009.tde-05052010-142132

ZABALZA, Miguel A. O ensino universitário: seu cenário e seus protagonistas. Porto Alegre: Artmed, 2004.

Recebido em: 31/7/2017.

Aprovado em: 20/12/2019.

Publicado em: 17/4/2020.

\section{Endereço para correspondência:}

Malu Santarem Schuh

Pontifícia Universidade Católica do Rio Grande do Sul

Av. Ipiranga, 6681 - Partenon

97010-082, Porto Alegre, RS, Brasil

\section{Autoras:}

Malu Santarem Schuh

Pontifícia Universidade Católica do Rio Grande do Sul, Porto Alegre, RS, Brasil.

Orcid: https://orcid.org/0000-0002-1837-1868

E-mail: malusantarems@gmail.com

Maria Elisabete Machado

Pontifícia Universidade Católica do Rio Grande do Sul, Porto Alegre, RS, Brasil.

Orcid: https://orcid.org/0000-0002-2369-9112

E-mail:mmelisabete@yahoo.com.br

Alam de Oliveira Casartelli

Pontifícia Universidade Católica do Rio Grande do Sul, Porto Alegre, RS, Brasil.

Orcid: https://orcid.org/0000-0002-7550-0769

E-mail: alam.casartelli@pucrs.br 